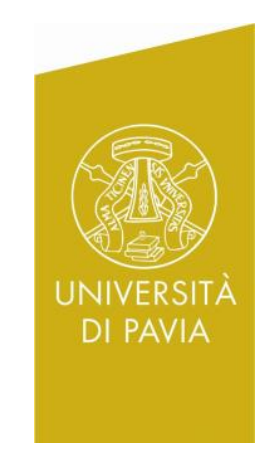

Department of Economics and Management DEM Working Paper Series

\title{
Inflation Bias and Markup Shocks in a LAMP Model with Strategic Interaction of Monetary and Fiscal Policy
}

\author{
Alice Albonico \\ (Università di Milano-Bicocca) \\ Lorenza Rossi \\ (Università di Pavia) \\ \# 133 (02-17) \\ Via San Felice, 5 \\ I-27100 Pavia \\ http://epmq.unipv.eu/site/home.html
}

February 2017 


\title{
Inflation bias and markup shocks in a LAMP model with strategic interaction of monetary and fiscal policy
}

\author{
Alice Albonico*and Lorenza Rossi ${ }^{\dagger}$
}

December 2016

\begin{abstract}
This paper investigates the effects generated by limited asset market participation on optimal monetary and fiscal policy, where monetary and fiscal authorities are independent and play strategically. It shows that: (i) both the long run and the short run equilibrium require a departure from zero inflation rate; (ii) in response to a markup shock, fiscal policy becomes more aggressive as the fraction of liquidity constrained agents increases and price stability is no longer optimal even under Ramsey; (iii) overall, optimal discretionary policies imply welfare losses for Ricardians, while liquidity constrained consumers experience welfare gains with respect to Ramsey.
\end{abstract}

Keywords: inflation bias, markup shocks, liquidity constrained consumers, optimal monetary and fiscal policy.

JEL codes: E3, E5.

*Dipartimento di Economia, Metodi Quantitativi e Strategie d'Impresa. Università di Milano Bicocca. Piazza dell'Ateneo Nuovo 1, Milano. Email: alice.albonico@unimib.it

†Dipartimento di Scienze Economiche e Aziendali. Università degli Studi di Pavia. Via San Felice 5, 27100 Pavia. Email: lorenza.rossi@unipv.it: Phone: +39 0382986486 


\section{Introduction}

In this paper we consider the strategic interactions between monetary and fiscal policy in an otherwise standard New Keynesian model characterized by limited asset market participation (LAMP henceforth). We model LAMP as it is now standard in the literature (see Mankiw 2000, Galí et al. 2004 and 2007 and Bilbiie 2008 among others). We assume that a fraction of households holds neither asset or firms and cannot access financial markets, thus it is liquidity constrained (LC), and in each period consumes all its disposable labor income. The remaining households are owner of the firms, hold assets and smooth consumption. This heterogeneity between households breaks the Ricardian Equivalence. For this reason, in the remainder of the paper we distinguish between non-Ricardian (or liquidity constrained) and Ricardian consumers.

We focus our analysis on three discretionary policy games: i) the Nash game; ii) the Fiscal Leadership game with conservative monetary policy; iii) the Monetary Leadership game with conservative monetary policy. In all games the fiscal and the monetary authority cannot commit, they take their policy decisions independently period by period and do not cooperate. The representative agents economy (RAE), where all agents are Ricardian, is considered as a benchmark for all the policy games. The comparison of the results of the LAMP model under each policy game with the corresponding results obtained under the RAE allow to capture the role played by LAMP in each game. The role played by the two authorities and their independence is instead clear when comparing different games under the same share of LAMP. In doing this, we first analyze the properties of the stochastic steady state for each policy game; then we look at the dynamics of the model showing the optimal impulse response functions in face of positive technology shocks and negative price markup shocks and the implied optimal inflation volatility. Finally, we analyze welfare implications.

We find that the presence of LAMP alters both the long-run and short run properties characterizing the policy games of a RAE. Regarding the steady state properties, we show that when the two policy authorities do not cooperate and cannot commit an inflation bias arises and it increases dramatically as the fraction of liquidity constrained consumers 
increases. The Central Bank annualized inflation target approaches $9 \%$ even for a fraction of non-Ricardian agents close to $30 \%$. The reason is the following. With respect to the standard RAE we have an additional source of inflation bias coming from the increase in the monopolistic distortion which occurs as the fraction of LC consumers gets higher. Indeed, since only Ricardians own firms, as LAMP increases, per capita profits earned by Ricardians get higher. Consequently, firms markups due to the monopolistic distortion increase and the aggregate output lowers. Since inflation acts as a tax on profits, by inflating the economy the Central Bank reduces firms markups and thus the distortion due to the presence of monopolistic competition. As a result, the higher the share of LAMP consumers the higher is the optimal steady state inflation rate.

Turning to the optimal dynamics, we find three main results. First, in line with the steady state result, the optimal inflation rate deviates from zero in response to both markup shocks and technology shocks under the two discretionary policies. In particular, in response to a technology shock the optimal inflation rate more than doubles, for a fraction of non-Ricardian agents passing from zero to about 50\%. Interestingly, the optimal inflation rate deviates from zero also under Ramsey in response to a markup shock. This is not surprising since markup shocks are usually found to be more difficult to stabilize with respect to technology shocks. Second, the markup shock implies that the optimal fiscal policy gets more aggressive the higher is LAMP. This last result holds for every policy regimes under analysis, suggesting the need of a more active role for the fiscal authority. Indeed, we find that the results are mainly driven by the dicretionary behavior of the policy authorities, while they are not particularly affected by the type of the dicretionary game considered.

Finally, we show that the optimal volatility of inflation increases with LAMP. Importantly, this occurs not only under the non-cooperative games, but also under Ramsey, due to the presence of markup shock.

The occurrence of the inflation bias has important implications also for welfare. In fact, we show that, contrary to what happens to Ricardian consumers, when the policy authorities are independent and cannot commit liquidity constrained agents get a welfare 
gain with respect to Ramsey, both in the short-run and in the long-run. This result suggests that, when the monetary authority and the fiscal authority play strategically, a sort of implicit redistribution characterizes the economy, since agents with lower income, i.e. LC consumers, experience a welfare gain, while Ricardian experience a loss in terms of welfare. ${ }^{1}$

In recent years, many authors concentrated on the issue of LAMP. In particular, they considered the presence of LAMP to break the Ricardian equivalence. This feature brought different results on the dynamics of the economies considered with respect to the standard framework. For example, Galí et al. (2007) demonstrate that the presence of LC consumers can explain consumption crowding in, which follows an increase in government spending. Bilbiie (2008) shows that LAMP can lead to the so called inverted aggregate demand logic. Di Bartolomeo and Rossi (2007) show that the effectiveness of monetary policy increases as LAMP becomes more important. Galí et al. (2004) study the determinacy properties in a model with LAMP and capital accumulation under different Taylor rules. These authors show that the presence of LAMP may alter the determinacy properties of a standard NK model. Finally, Colciago (2011) and Furlanetto (2011) extend the analysis in Galí et al. (2007) to the case of nominal wage stickiness. ${ }^{2}$ However, none of these papers consider the strategic interactions between monetary and fiscal policy and the relative optimal policies prescriptions.

In addition, most of the literature studying fiscal and monetary policy assumes that they are both driven by a unique authority (Schmitt-Grohé and Uribe 2004a, 2004b, 2007 among others). This is clearly not the case nowadays and in particular in the EU context, where the creation of the currency area led to a structure with a unique monetary authority and several independent fiscal authorities. ${ }^{3}$ In such a context it

\footnotetext{
${ }^{1}$ Allowing for a redistributive fiscal policy is beyond the scope of this paper. For a detailed analysis of this issue see Albonico and Rossi (2015).

${ }^{2}$ They also show that the results obtained by Bilbiie (2008) hold for values of LC consumers which are not empirically relevant. Similarly, Ascari et al. (2011) find that the implications of LAMP for the design of optimal monetary policy are minor under sticky wages. Motta and Tirelli (2012) show that a significant role for LAMP is restored when habits in consumption are introduced, even in the presence of wage stickiness.

${ }^{3}$ We are aware that there should be caution in interpreting our results in the light of the European situation, since we consider a single fiscal authority. Nevertheless, notice that European fiscal policies are strongly coordinated, since budget deficits are approved at the EU level. In this respect, assuming
} 
is then relevant to investigate the strategic interactions between the Central Bank and the fiscal authority, as done by Gnocchi (2008), Beetsma and Jensen (2005), Adam and Billi (2008) among others. Gnocchi (2008) and Beetsma and Jensen (2005) consider NK open economies models with a representative Ricardian consumer and analyze the role of fiscal policy stabilization. ${ }^{4}$ Finally, Adam and Billi (2008) concentrate on a closed economy environment and study monetary and fiscal policies without commitment in an NK Ricardian economy. They find that the lack of commitment gives rise to excessive public spending and only moderate positive optimal inflation rate in steady state. Adam and Billy (2008) mainly focus on the steady state proprieties of their model. Thus, in this respect we make a step forward, not only by introducing LAMP but also by considering the optimal dynamics of the model, focusing especially on the optimal inflation dynamics and volatility under the different policy regimes.

Overall, all these papers do not address the issue of LAMP together with the strategic interactions between monetary and fiscal authority. To the best of a our knowledge, the only exception is Albonico and Rossi (2015) which analyses these interactions in the presence of LAMP focusing mainly on redistributive issues and considers only the optimal responses to a technology shock. In this paper we do not study redistributive policies, however we concentrate on the role of the markup shock, which is an important source for business cycle transmission. ${ }^{5}$

The paper is organized as follows. Section 2 presents some empirical evidence on the tightening of the conditions of access to credit. Section 3 introduces the model, while section 4 presents the different policy regimes and analyzes the optimal stochastic steady

a single fiscal authority can be viewed as a simple shortcut for representing fiscal policies coordination. Nevertheless, the main objective of this paper is to analyze the role played by LAMP in changing the optimal behaviour of interacting policy makers; it is not to suggest any policy prescription for the European authorities as well as for the US ones.

${ }^{4}$ Gnocchi (2008) analyzes the effects of fiscal discretion in a currency area, where a common and independent monetary authority commits to optimally set the union-wide nominal interest rate. The main result is that discretion entails significant welfare costs so that it is not optimal to use fiscal policy as a stabilization tool. Instead, Beetsma and Jensen (2005) investigate the role of policy commitment in a micro-founded New-Keynesian model of a two-country monetary union, finding that monetary policy with identical union members is concerned with stabilizing the union-wide economy, fiscal policy aims at stabilizing inflation differences and the terms of trade.

${ }^{5}$ The importance of these shocks has been confirmed by many empirical papers, such as Smets and Wouters (2003,2007) and Rabanal and Rubio-Ramirez (2005). 
state and optimal dynamics in response to technology and markup shocks. In section 5 we study the welfare implications. Section 6 concludes.

\section{The recent tightening of credit}

Since August 2007, starting date of the recent financial crisis, there has been a strong increase in credit constraints. Questions regarding bank solvency have caused not only an interbank credit crunch but also a decline in credit availability of households. The main factors contributing to the decline in credit availability were the bad expectations regarding general economic activity and housing market prospects as well as cost of funds and balance sheet constraints for banks.

In this section we show some empirical evidence on the decline of banking lending to households, for housing and other consumer credit, in the Euro area and in the $\mathrm{US}^{6}$. Figures 1 and 2 show the behavior of credit standards for the period 2003-2012.

As shown in Figure 1 credit standards tightened in the Euro area since the first months of 2008. The tightening reached its maximum value in April 2009 and then started decreasing. Nevertheless, if we exclude the forth quarter of 2010 where no tightening were perceived, banks still report tightening in credit standards during the last years, which remain higher than in the pre-crisis period.

As shown in Figure 2, in the US the tightening of credit standards started in the mid of 2007, before the EU, and was even stronger than in the Euro area. These features of the US credit standards are not surprising since the financial crisis was triggered by a liquidity shortfall in the United States banking system at the beginning of the summer 2007, which afterwards spread all over the Euro area and most of the industrialized countries. Contrary to the Euro Area, the tightening partly reabsorbed after the first quarter of 2010. However, credit standards may not be back to pre-crisis levels, since the Survey refers to the perception of change in credit standards with respect to the previous three months. Thus, even an unchanged perception in credit standards indicates that they

\footnotetext{
${ }^{6}$ Data for the euro area are taken from The Euro Area Bank Lending Survey of the European Central Bank. Data for the US are taken from the Senior Loan Officer Opinion Survey on Bank Lending Practices of the Federal Reserve Board.
} 
have remained high and close to the crisis level. Overall, the evidence on credit standards shows a sharp decline of credit to households since the beginning of the crisis.

Also notice that, the recent crisis is not the main motivation of our paper. We refer to the crisis only for saying that during this period the proportion of LAMP households has increased. However, the presence of LAMP seems to be important even in normal times and not only in crisis periods. An example are the empirical studies are of Coenen and Straub (2005), and Kaplan et al. (2014). The latter reports values for the fraction of hand-to-mouth (LAMP) consumers in between 0.2 and 0.4 for G7 countries, while the former find similar values. Forni et al. (2009) find a fraction of non-Ricardian agents, close to $40 \%$, while Di Bartolomeo et al. (2011) report an average fraction of non-Ricardian agents of about $26 \%$ for the G7 countries. More recently, Albonico et al. (2014, 2016a, 2016b) find a share of LAMP comprised between $25 \%$ and $53 \%$ for the Euro area and $47 \%$ for US. Overall, we can state that the estimated value of LAMP is in between 0.25 and 0.53. Thus, considering the role played by these households in the business cycle is crucial for the design of the optimal fiscal and monetary policy.

\section{The model}

\subsection{Households}

The model economy consists of a continuum of infinitely-lived households. Households are divided into a fraction $1-\lambda$ of 'Ricardians' who smooth consumption and have access to assets markets; the remaining fraction $\lambda$ are the so called 'liquidity constrained' consumers who have no assets and spend all their current disposable labor income for consumption each period. Both types of households have the same preferences structure. Only Ricardian agents own the firms and thus the capital stock. The utility functions for Ricardians and rule for thumb consumers are then respectively:

$$
u\left(C_{t}^{o}, N_{t}^{o}, G_{t}\right)=\frac{C_{t}^{o 1-\sigma}}{1-\sigma}-\omega_{n} \frac{N_{t}^{o 1+\varphi}}{1+\varphi}+\omega_{g} \frac{G_{t}^{1-\sigma}}{1-\sigma}
$$


and

$$
u\left(C_{t}^{r}, N_{t}^{r}, G_{t}\right)=\frac{C_{t}^{r 1-\sigma}}{1-\sigma}-\omega_{n} \frac{N_{t}^{r 1+\varphi}}{1+\varphi}+\omega_{g} \frac{G_{t}^{1-\sigma}}{1-\sigma}
$$

Following Galí et al. (2004 and 2007) $C_{t}^{o}, N_{t}^{o}$ are Ricardian consumer's consumption and hours worked, $C_{t}^{r}, N_{t}^{r}$ are liquidity constrained consumer's consumption and hours worked and $G_{t}$ is public expenditure. Utility is separable in $C, N, G$ and $U_{c}>0, U_{c c}<0, U_{n}<0$, $U_{n n} \leq 0, U_{g}>0, U_{g g}<0$.

Ricardians' budget constraint is:

$$
P_{t} C_{t}^{o}+\frac{B_{t}}{1-\lambda}=R_{t-1} \frac{B_{t-1}}{1-\lambda}+P_{t} w_{t} N_{t}^{o}-P_{t} T_{t}^{o}+\frac{D_{t}}{1-\lambda}
$$

where $P_{t}$ is the nominal price index, $R_{t}$ is the gross nominal interest rate, $B_{t}$ represents the nominal value of the privately issued and purchased assets by Ricardians in $t$ and maturing in $t+1, w_{t}$ is the real wage paid in a competitive labor market, $T_{t}^{o}$ are lump sum taxes and $D_{t}$ are profits of monopolistic firms.

The Ricardians' problem consists of choosing $\left\{C_{t}^{o}, N_{t}^{o}, B_{t}\right\}_{t=0}^{\infty}$ to maximize $E_{0} \sum_{t=0}^{\infty} \beta^{t} u\left(C_{t}^{o}, N_{t}^{o}, G_{t}\right)$ subject to (3), taking as given $\left\{P_{t}, w_{t}, R_{t}, G_{t}, T_{t}, D_{t}\right\} .{ }^{7}$ From the first order condition we get:

$$
w_{t}=\frac{\omega_{n} N_{t}^{o \varphi}}{C_{t}^{o-\sigma}}
$$

and

$$
\frac{C_{t}^{o-\sigma}}{R_{t}}=\beta E_{t} \frac{C_{t+1}^{o}{ }^{-\sigma}}{\pi_{t+1}}
$$

Liquidity constrained consumers each period solve a static problem: they maximize their period utility (2) subject to the constraint that all their disposable income is consumed:

\footnotetext{
${ }^{7}$ The no-Ponzi scheme constraint $\lim _{j \rightarrow \infty} E_{t} \prod_{i=0}^{t+j-1} \frac{1}{R_{t}} B_{t+j} \geq 0$ and the transversality condition $\lim _{j \rightarrow \infty} E_{t} \beta^{t+j} C_{t+j}^{o}{ }^{-\sigma} B_{t+j} / P_{t+j}=0$ hold.
} 


$$
P_{t} C_{t}^{r}=P_{t} w_{t} N_{t}^{r}-P_{t} T_{t}^{r}
$$

From the first order conditions we get:

$$
w_{t}=\frac{\omega_{n} N_{t}^{r \varphi}}{C_{t}^{r-\sigma}}
$$

As we will explain later in the paper, firms are indifferent with respect to the type of consumer to hire, therefore labor is homogenous and the two consumers get the same paid $w_{t}$. This leads to the following condition:

$$
\frac{N_{t}^{o \varphi}}{C_{t}^{o-\sigma}}=\frac{N_{t}^{r \varphi}}{C_{t}^{r-\sigma}}
$$

which equals the ratio between the marginal utilities of Ricardian and liquidity constrained consumers respectively.

The aggregate consumption and hours worked are defined as follows:

$$
\begin{gathered}
C_{t}=\lambda C_{t}^{r}+(1-\lambda) C_{t}^{o} \\
N_{t}=\lambda N_{t}^{r}+(1-\lambda) N_{t}^{o} .
\end{gathered}
$$

\section{$3.2 \quad$ Firms}

There is a continuum of intermediate goods, indexed by $i \in[0,1]$ and a sector of final good which uses the technology: $Y_{t}=\left[\int_{0}^{1} Y_{t}(i)^{\frac{\epsilon_{t}-1}{\epsilon_{t}}} d j\right]^{\frac{\epsilon_{t}}{\epsilon_{t}-1}}$. The sector of final good operates in perfect competition. Then profit maximization implies $Y_{t}(i)=\left(\frac{P_{t}(i)}{P_{t}}\right)^{-\epsilon_{t}} Y_{t}$, where $\epsilon_{t}$ represents the elasticity of substitution across varieties and is assumed to be an $\mathrm{AR}(1)$ process $\log \left(\epsilon_{t} / \epsilon\right)=\rho_{\epsilon} \log \left(\epsilon_{t} / \epsilon\right)+s_{t}^{\epsilon}$, with $0<\rho_{\epsilon}<1$ and $s_{t}^{\epsilon}$ normally distributed innovation with zero mean and standard deviation $\sigma_{\epsilon} . \epsilon_{t}$ is time-varying, thus induces $\ddagger$ fluctuations in the monopolistic markup charged by firms. $P_{t}$ is defined as $P_{t}=\left[\int_{0}^{1} P_{t}(i)^{1-\epsilon_{t}} d i\right]^{\frac{1}{1-\epsilon_{t}}}$. The intermediate good sector is characterized by firms producing each a differentiated good with a technology represented by a Cobb-Douglas production function with a unique factor of 
production (aggregate labor) and constant returns to scale:

$$
Y_{t}(i)=Z_{t} N_{t}(i)
$$

where $\log \left(Z_{t} / Z\right)=z_{t}$ is an aggregate productivity shock with $\operatorname{AR}(1)$ process:

$$
z_{t}=\rho_{z} z_{t-1}+s_{t}^{z}
$$

$0<\rho_{z}<1$ and $s_{t}^{z}$ is a normally distributed serially uncorrelated innovation with zero mean and standard deviation $\sigma_{z}$. In this context each firm $i$ has monopolistic power in the production of its own good and therefore it sets the price. Prices are sticky à la Rotemberg (1982) so that firms face quadratic resource costs for adjusting nominal prices according to: $\frac{\theta}{2}\left(\frac{P_{t}(i)}{P_{t-1}(i)}-1\right)^{2}$, where $\theta$ is the degree of price rigidities.

The problem of the firm is then to choose $\left\{P_{t}(i), N_{t}(i)\right\}_{t=0}^{\infty}$ to maximize the sum of expected discounted profits:

$$
\begin{array}{r}
\max _{\left\{N_{t}(i), P_{t}(i)\right\}} E_{0} \sum_{t=0}^{\infty} \beta^{t} \frac{\gamma_{t}}{\gamma_{0}}\left\{\frac{P_{t}(i)}{P_{t}} Y_{t}(i)-w_{t} N_{t}(i)-\frac{\theta}{2}\left(\frac{P_{t}(i)}{P_{t-1}(i)}-1\right)^{2}\right\} \\
\text { s.t. } Y_{t}(i)=\left(\frac{P_{t}(i)}{P_{t}}\right)^{-\epsilon_{t}} Y_{t}=Z_{t} N_{t}(i)
\end{array}
$$

where $Y_{t}=C_{t}+G_{t}$ and $\gamma_{t}=C_{t}^{o-\sigma}$ is the marginal utility of consumption of Ricardians households. Notice that, since Ricardians are the owners of firms, they discount their profits using their stochastic discount factor, which depends only on their consumption decisions and corresponds to the market real interest rate.

In equilibrium all firms will charge the same price, so that we can impose symmetry. After defining $m c_{t}$ as the real marginal cost, the FOCs are:

$$
\begin{gathered}
w_{t}=m c_{t} Z_{t} \\
0=\left[1-\left(1-m c_{t}\right) \epsilon_{t}\right] Y_{t}-\theta\left(\pi_{t}-1\right) \pi_{t}+\theta \beta E_{t}\left(\frac{C_{t+1}^{o}-\sigma}{C_{t}^{o-\sigma}}\right)\left(\pi_{t+1}-1\right) \pi_{t+1} .
\end{gathered}
$$

Combining (14) with (4) and (7) yields to such an expression for the real marginal 
cost:

$$
m c_{t}=\frac{1}{Z_{t}}\left(\lambda \omega_{n} N_{t}^{r \varphi} C_{t}^{r \sigma}+(1-\lambda) \omega_{n} N_{t}^{o \varphi} C_{t}^{o \sigma}\right)
$$

Then, we combine it with (15) and get:

$$
\begin{array}{r}
C_{t}^{o-\sigma}\left(\pi_{t}-1\right) \pi_{t}=\left[1-\left(1-\frac{\lambda \omega_{n} N_{t}^{r \varphi} C_{t}^{r \sigma}+(1-\lambda) \omega_{n} N_{t}^{o \varphi} C_{t}^{o \sigma}}{Z_{t}}\right) \epsilon_{t}\right] \frac{Z_{t} N_{t} C_{t}^{o-\sigma}}{\theta} \\
+\beta E_{t} C_{t+1}^{o-\sigma}\left(\pi_{t+1}-1\right) \pi_{t+1}
\end{array}
$$

\subsection{Government}

The government is composed by a monetary authority which sets the nominal interest rate $R_{t}$ and a fiscal authority which determines the level of public expenditure $G_{t}$. The government runs a balanced budget, so that in each period public consumption equals lump sum taxes ${ }^{8}$.

$$
P_{t} G_{t}=P_{t} T_{t}
$$

Defining aggregate lump sum taxes as $T_{t}=\lambda T_{t}^{r}+(1-\lambda) T_{t}^{o}$, if the same amount of lump sum taxes is withdrawn from each individual $\left(T_{t}^{r}=T_{t}^{o}\right)$, we obtain $G_{t}=T_{t}=T_{t}^{r}=T_{t}^{o}$.

\subsection{Equilibrium}

To close the model we consider also the goods market clearing condition:

$$
Z_{t}\left[\lambda N_{t}^{r}+(1-\lambda) N_{t}^{o}\right]=\lambda C_{t}^{r}+(1-\lambda) C_{t}^{o}+G_{t}+\frac{\theta}{2}\left(\pi_{t}-1\right)^{2}
$$

A rational expectations equilibrium for the private sector consists of a plan $\left\{C_{t}^{r}, C_{t}^{o}, N_{t}^{r}, N_{t}^{o}, P_{t}\right\}$ satisfying (5), (6), (8), (17) and (19), given the policies $\left\{G_{t}, T_{t}, R_{t} \geq 1\right\}$ and the exogenous processes $\epsilon_{t}, Z_{t}$.

\footnotetext{
${ }^{8}$ We leave the introduction of public debt to future research.
} 


\section{Policy games}

In this section we present the structure of the different policy games analyzed in the paper. First, we will introduce the Ramsey problem, which allows for policy commitment at time zero and full cooperation between monetary and fiscal policy authorities. Then, three different games structures will be presented: 1) the Nash game; 2) the Fiscal Leader game (FL); 3) Monetary Leader game (ML) In all cases, the two authorities cannot commit and take their decisions separately period by period. The equations for the solution of the Ramsey equilibrium and those of the different game structures are presented in the appendix ${ }^{9}$

Ramsey Policy. In this case the policy authorities fully cooperate and can commit, which means that policy makers determine state-contingent future policies at time zero. Differently from the standard Social Planner problem, the Ramsey allocation takes into account the distortions characterizing the model economy, i.e., sticky prices and monopolistic distortions. Therefore, Ramsey solution corresponds to a second best allocation solving the following problem:

$$
\begin{array}{r}
\max _{\left\{C_{t}^{r}, N_{t}^{r}, C_{t}^{o}, N_{t}^{o}, \pi_{t}, R_{t}, G_{t}\right\}} E_{0} \sum_{t=0}^{\infty} \beta^{t}\left\{\lambda u\left(C_{t}^{r}, N_{t}^{r}, G_{t}\right)+(1-\lambda) u\left(C_{t}^{o}, N_{t}^{o}, G_{t}\right)\right\} \\
\text { s.t. }(5),(6),(8),(17),(18),(19) \text { for all t . }
\end{array}
$$

where constraints $(5),(6),(8),(17),(18),(19)$ represent the equilibrium of the competitive economy.

Before introducing the structures of the policy games it is worth to notice that the competitive equilibrium of our model does not include any endogenous state variable. This happens because, as in Adam and Billi (2008) we consider: i) a cash-less economy; ii) a Government running a balanced budget; iii) labor as the only input in the production function. As a consequence, the endogenous variables, that is consumption, output and inflation are pure forward looking variables. Since the only state variables are the exogenous shocks, the equilibrium outcomes of our games are completely forward looking and

\footnotetext{
${ }^{9}$ The technical appendix is available on the authors' webpages.
} 
thus easily tractable. This modelling choice give us the opportunity to directly compare our results with those obtained by Adam and Billi (2008), by easily disentangling the role played by LC consumers.

In what follows we present the structure of the policy games. The fiscal authority sets the level of Government spending, while the monetary authority sets the nominal interest rates and thus indirectly it controls the inflation rate. Further, each policy maker takes as given the current policy choice of the other policy maker, as well as all future policies and future private sector choices. As stressed by Adam and Billi (2008), this creates a conflicts between the two authorities that leads to an excessive spending for the fiscal authority and to a strictly positive steady state inflation, that is to an inflation bias, for the monetary authority.

Nash Game. In this case, policy makers do not cooperate and cannot commit, decide their policy simultaneously and period by period (i.e. they are just choosing variables for the current period), by taking state-contingent variables as given.

The problem of the fiscal authority is therefore:

$$
\begin{array}{r}
\max _{\left\{C_{t}^{r}, N_{t}^{r}, C_{t}^{o}, N_{t}^{o}, \pi_{t}, G_{t}\right\}} E_{t} \sum_{t=0}^{\infty} \beta^{t}\left\{\lambda u\left(C_{t}^{r}, N_{t}^{r}, G_{t}\right)+(1-\lambda) u\left(C_{t}^{o}, N_{t}^{o}, G_{t}\right)\right\} \\
\text { s.t. }(5),(6),(8),(17),(18),(19) \text { for all t } \\
\left\{C_{t+j}^{r}, C_{t+j}^{o}, N_{t+j}^{r}, N_{t+j}^{o}, \pi_{t+j}, R_{t+j-1} \geq 1, G_{t+j}\right\} \text { given for } j \geq 1 .
\end{array}
$$

The set of first order conditions define the behavior of the fiscal policy maker and thus, its fiscal reaction function (FRF henceforth). Analogously, the monetary authority solves the following problem:

$$
\begin{array}{r}
\max _{\left\{C_{t}^{r}, N_{t}^{r}, C_{t}^{o}, N_{t}^{o}, \pi_{t}, R_{t}\right\}} E_{t} \sum_{t=0}^{\infty} \beta^{t}\left\{\lambda u\left(C_{t}^{r}, N_{t}^{r}, G_{t}\right)+(1-\lambda) u\left(C_{t}^{o}, N_{t}^{o}, G_{t}\right)\right\} \\
\text { s.t. }(5),(6),(8),(17),(18),(19) \text { for all t } \\
\left\{C_{t+j}^{r}, C_{t+j}^{o}, N_{t+j}^{r}, N_{t+j}^{o}, \pi_{t+j}, R_{t+j} \geq 1, G_{t+j-1}\right\} \text { given for } j \geq 1 .
\end{array}
$$

As for the fiscal authority, the set of first order conditions define the behavior of 
the monetary policy maker and thus, its monetary reaction function (MRF henceforth). The Nash equilibrium with sequential monetary and fiscal policy consists of the following time-invariant policy functions $C^{r}\left\{Z_{t}, \epsilon_{t}\right\}, C^{o}\left\{Z_{t}, \epsilon_{t}\right\}, N^{r}\left\{Z_{t}, \epsilon_{t}\right\}, N^{o}\left\{Z_{t}, \epsilon_{t}\right\}, \pi\left\{Z_{t}, \epsilon_{t}\right\}$, $R\left\{Z_{t}, \epsilon_{t}\right\}, G\left\{Z_{t}, \epsilon_{t}\right\}$ solving equations (5), (6), (8), (17), (18), (19), the FRF and the MRF.

Fiscal Leadership game. As for the Nash game, policy makers cannot commit and decide about policies period by period. Unlike the Nash game however, the fiscal policy is determined before the monetary policy. Therefore, in this context, the fiscal authority behaves as the Stackelberg leader, while the monetary authority is the Stackelberg follower.

The Stackelberg structure becomes relevant only when the utility functions of the monetary or the fiscal authority are different ${ }^{10}$. Thus, we assume that the monetary authority is more inflation averse than society, following Rogoff (1985) and Adam and Billi (2008). The idea is that a conservative monetary authority is closer to the ECB's mandate of maintaining price stability. The objective function of the monetary policy maker is a weighted sum of agents' utility and a cost of inflation, so that the monetary authority now solves the following:

$$
\begin{array}{r}
\max _{\left\{C_{t}^{r}, N_{t}^{r}, C_{t}^{o}, N_{t}^{o}, \pi_{t}, R_{t}\right\}} E_{t} \sum_{t=0}^{\infty} \beta^{t}\left\{(1-\alpha)\left[\lambda u\left(C_{t}^{r}, N_{t}^{r}, G_{t}\right)+(1-\lambda) u\left(C_{t}^{o}, N_{t}^{o}, G_{t}\right)\right]-\alpha \frac{\left(\pi_{t}-1\right)^{2}}{2}\right\} \\
\text { s.t. }(5),(6),(8),(17),(18),(19) \text { for all t } \\
\left\{C_{t+j}^{r}, C_{t+j}^{o}, N_{t+j}^{r}, N_{t+j}^{o}, \pi_{t+j}, R_{t+j} \geq 1, G_{t+j-1}\right\} \text { given for } j \geq 1 .
\end{array}
$$

where $\alpha \in[0,1]$ is a measure of monetary conservatism. Notice that, $0<\alpha<1$ means that the monetary authority dislikes inflation more than society and the Central Bank is defined as partially conservative. Instead, when $\alpha=1$ the policy maker only cares about inflation and is defined as fully conservative.

Given that the fiscal authority is the Stackelberg leader, fiscal policy is determined before monetary policy and it takes into account the conservative monetary policy reaction

\footnotetext{
${ }^{10} \mathrm{We}$ find that otherwise both the monetary leadership and the fiscal leadership in this case collapse to the Nash game. Results are available upon requests.
} 
function, which consists of the first order conditions of (23). The fiscal policy problem at time $t$ is thus given by:

$$
\begin{array}{r}
\max _{\left\{C_{t}^{r}, N_{t}^{r}, C_{t}^{o}, N_{t}^{o}, \pi_{t}, R_{t}, G_{t}\right\}} E_{t} \sum_{t=0}^{\infty} \beta^{t}\left\{\lambda u\left(C_{t}^{r}, N_{t}^{r}, G_{t}\right)+(1-\lambda) u\left(C_{t}^{o}, N_{t}^{o}, G_{t}\right)\right\} \\
\text { s.t. }(5),(6),(8),(17),(18),(19), \text { FOCs of }(23) \text { for all t } \\
\left\{C_{t+j}^{r}, C_{t+j}^{o}, N_{t+j}^{r}, N_{t+j}^{o}, \pi_{t+j}, R_{t+j} \geq 1, G_{t+j}\right\} \text { given for } j \geq 1 .
\end{array}
$$

Monetary Leadership game. As for the previous game the authorities cannot commit and decide about policies period by period. In this case, the monetary policy is determined before the fiscal policy. Therefore, in this context, the monetary authority behaves as the Stackelberg leader, while the fiscal authority is the Stackelberg follower. Also in this case the monetary authority is more inflation averse than society.

The problem of the fiscal policy maker corresponds to the one under Nash (21). Given that the monetary authority is the Stackelberg leader, monetary policy is determined before fiscal policy and it takes into account the fiscal policy reaction function, which consists of the first order conditions of 21 . The monetary policy problem at time $t$ is thus given by:

$$
\begin{array}{r}
\max _{\left\{C_{t}^{r}, N_{t}^{r}, C_{t}^{o}, N_{t}^{o}, \pi_{t}, R_{t}, G_{t}\right\}} E_{t} \sum_{t=0}^{\infty} \beta^{t}\left\{(1-\alpha)\left[\lambda u\left(C_{t}^{r}, N_{t}^{r}, G_{t}\right)+(1-\lambda) u\left(C_{t}^{o}, N_{t}^{o}, G_{t}\right)\right]-\alpha \frac{\left(\pi_{t}-1\right)^{2}}{2}\right\} \\
\text { s.t. }(5),(6),(8),(17),(18),(19), \text { FOCs of } 21 \text { for all t } \\
\left\{C_{t+j}^{r}, C_{t+j}^{o}, N_{t+j}^{r}, N_{t+j}^{o}, \pi_{t+j}, R_{t+j} \geq 1, G_{t+j}\right\} \text { given for } j \geq 1 .
\end{array}
$$

\subsection{Calibration}

The model steady state and dynamics are solved numerically after calibrating the parameters. From now on, we will refer to the calibration shown in Table 1 which is in line with Adam and Billi (2008) and Albonico Rossi (2015). 


\begin{tabular}{c|c|c}
\hline \hline parameters & value & source \\
\hline \hline$\beta$ & 0.9913 & Adam and Billi (2008) \\
$\theta$ & 17.5 & Adam and Billi (2008) and Schmitt-Grohé and Uribe (2007) \\
$\sigma$ & 1 & in line with Adam and Billi (2008) log utility function \\
$\varphi$ & 1 & Adam and Billi (2008) \\
$\omega_{n}$ & 26.042 & Adam and Billi (2008) \\
$\omega_{g}$ & 0.227 & Adam and Billi (2008) \\
$\epsilon$ & 6 & Adam and Billi (2008) and Galì et al. (2004) \\
$Z$ & 1 & Adamd Billi (2008) \\
$\lambda(\mathrm{SS})$ & varying & \\
$\lambda($ dynamics $)$ & 0.5 & Campbell and Mankiw (1989) and Galì et al. (2004) \\
$\rho_{z}$ & 0.9 & \\
$\rho_{\epsilon}$ & 0.9 & \\
$\sigma_{z}$ & 0.01 & \\
$\sigma_{\epsilon}$ & 0.01 & \\
\hline \hline
\end{tabular}

Table 1: Calibration

\subsection{The optimal stochastic steady state}

Ramsey steady state. From the first order conditions we derive that the value of $\pi_{t}$ in steady state is 1 , which implies price stability. Then, from the Euler equation we find that $R=1 / \beta$. Combining these results with (17) we get the following:

$$
w=\left[\lambda \frac{\omega_{n} N^{r \varphi}}{C^{r^{-\sigma}}}+(1-\lambda) \frac{\omega_{n} N^{o \varphi}}{C^{o^{-\sigma}}}\right]=\frac{\epsilon-1}{\epsilon}
$$

which implies that the steady state real wage does not depend on the fraction of rule of thumb consumers. Equation (26) resembles the equilibrium result under flexible prices, where steady state real marginal costs equal the inverse of the desired markup.

Table 2 resumes the steady state values under all policy games. ${ }^{11}$ Notice that, we consider three alternative values for the fraction of LC consumers, that is $\lambda=(0 ; 0.3 ; 0.5)$. When $\lambda=0$, our model nests the RAE model, which is used as a benchmark model. Empirical evidence on limited asset market participation found values in between 0.3 and 0.5. In particular, Campbell and Mankiw (1989) as well as Muscatelli et al. (2004) among others, estimate a value of $\lambda$ equal to 0.5. Forni et al. (2009) find a fraction

\footnotetext{
${ }^{11}$ The tables present the result in terms of the stochastic steady state under a $1 \%$ standard deviation for both shocks.
} 
of non-Ricardian agents, close to 40\%, while Di Bartolomeo et al. (2011) report an average fraction of non-Ricardian agents of about $26 \%$ for the G7 countries. More recently, Albonico et al. (2014, 2016a, 2016b) find a share of LAMP comprised between $25 \%$ and $53 \%$ for the Euro area, and $47 \%$ for US. Kaplan et al. (2014), also report values in between 0.2 and 0.4 for G7 countries. As shown in Table 2, while the steady state inflation rate is always equal to 1 , no matter the value of $\lambda$, public spending reduces with $\lambda$ increasing, even if only marginally. Moreover, notice that consumption of Ricardian households, $C^{o}$, is an increasing function of $\lambda$. The reason is the following. As $\lambda$ increases, the fraction of Ricardians decreases so that per capita profits $D /(1-\lambda)$ rise, boosting per capita Ricardian consumption. Liquidity constrained consumption slightly increases as $\lambda$ becomes greater than 0.3 due to a small reduction of $G$. In fact, the steady state of the Government budget constraint implies $G=T=T^{o}=T^{r}$, and therefore from (6) we obtain $C^{r}=w N^{r}-G$. It is easy to understand that the more than proportional decrease in $G$ with respect to $N^{r}$ causes $C^{r}$ to rise, since the steady state value of the real wage is constant. Therefore, from the policy authority point of view, it is optimal to reduce public spending to maximize welfare when $\lambda$ increases, because it rises $C^{r}$.

Nash steady state. We find the steady state of the Nash game through numerical methods. Table 3 shows the results.

As pointed out by Adam and Billi (2008), when the policy authorities play simultaneously and under discretion there is an inflation bias with respect to the Ramsey steady state. In our model, however, the inflation bias increases dramatically as the fraction of liquidity constrained households $\lambda$ gets higher. The Central Bank annualized inflation target approaches $9 \%$ even for a small fraction of non-Ricardian agents close to $30 \%$. This value is about $14 \%$ when the fraction of LC consumers is 0.5 . The intuition is straightforward. The inflation bias arises because the monetary authority disregards private expectations on inflation. Limited asset market participation is an additional distortion in the economy with respect to the two usually faced by the Central Bank, i.e.: i) the monopolistic competition distortion; ii) the sticky price distortion. The first one reduces as the steady state inflation increases. This happens because the inflation rate acts as an implicit tax 
on profits. On the contrary, the sticky price distortion calls for price stability for reducing the price adjustment costs. When $\lambda$ increases, per capita profits earned by Ricardians, i.e. $D /(1-\lambda)$, get higher and the monopolistic distortion increases. By increasing the steady state inflation rate the Central Bank reduces the monopolistic distortion and increases the steady state output. Overall, the monopolistic distortion becomes more and more relevant as the fraction of LC consumers increases. ${ }^{12}$ Therefore, the optimal steady state inflation remains highly positive for empirically plausible values of the Rotemberg adjustment $\operatorname{costs}^{13}$ and increases as $\lambda$ gets higher.

Finally, we also find a government spending bias, as in the RAE. However, this bias is only marginally affected by LC consumers. This happens because the fiscal authority takes into account that an increase in public spending has two effects. First, government spending enters directly households' utility function. Therefore, an increase in spending increases welfare. Second, an increase in $G$, by implying higher taxes, reduces LC consumers disposable income and thus their consumption and welfare. This second effect does not concern Ricardian agents since they have an additional source of income represented by profits.

Fiscal Leader steady state. Table 2 shows that the optimal steady state values under the FL with a partially conservative monetary policy $(\alpha=0.5)$ change only marginally with respect to the Nash case.

Monetary Leader steady state. Table 2 shows that also the optimal steady state values under the ML with a partially conservative monetary policy $(\alpha=0.5)$ change only

\footnotetext{
${ }^{12} \mathrm{We}$ also consider the case where not only Ricardians but also LC consumers receive income from profits. In this case the extra-inflation bias reduces significantly, even if not completely. The reason is the following. Since also LC consumers receive income from profits, ceteris paribus they get an higher disposable income with respect to the baseline model. Thus, the Central Bank has a lower incentive to use the inflation tax as a redistributive policy from Ricardian to LC consumers. Results are available upon request.

${ }^{13} \mathrm{We}$ consider also a value of $\theta$ alternative to the baseline value consider by Adam and Billi (2008). We translate the cost of adjusting prices into an equivalent Calvo probability, i.e. $\theta=\frac{\varepsilon-1}{\kappa}$, where $\kappa=\frac{(1-\psi)(1-\psi \beta)}{\psi}$ and $\psi=0.75$ is the Calvo probability that firms do not adjust prices. This allows to generate a slope of the Phillips curve consistent with empirical and theoretical studies. We get a value of $\theta=58$, which is more than three times higher than the one considered by Adam and Billi (2008). The results about the inflation bias remains relevant although the optimal steady state inflation slightly lowers.
} 


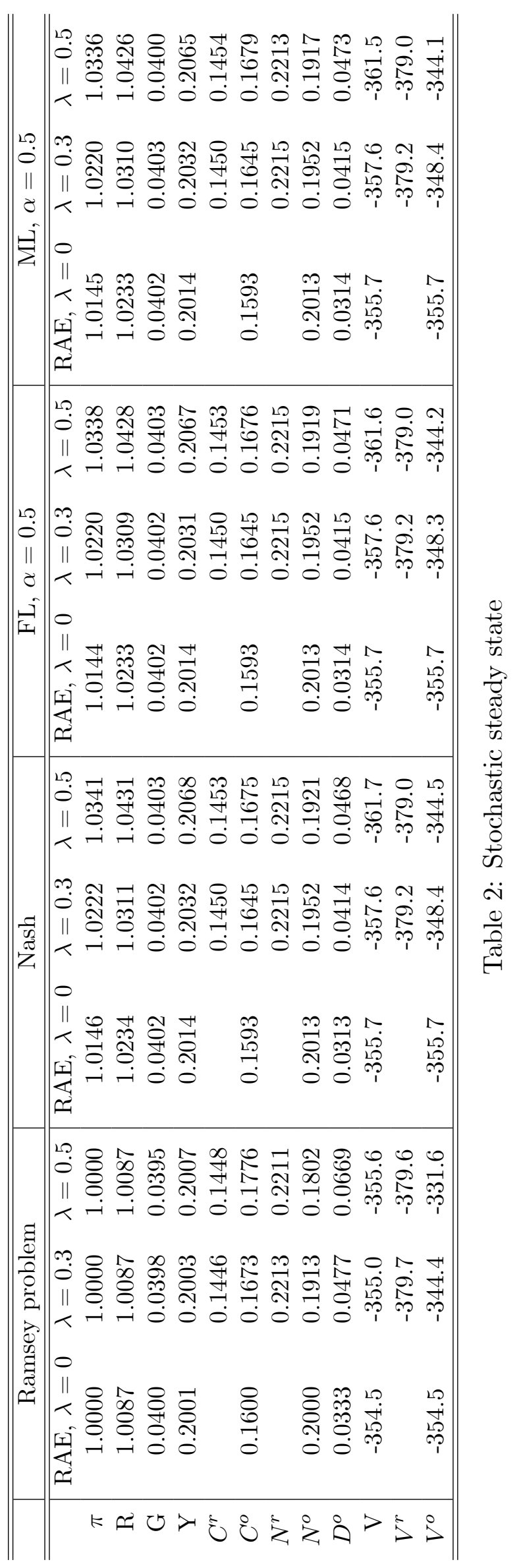


marginally with respect to the Nash case.

Overall, we find that under the Nash game, the FL game and the ML with partially conservative Central Bank, the optimal monetary policy implies an inflation bias which strongly increases as the fraction of LC consumers, $\lambda$, increases. ${ }^{14}$

\subsection{The optimal dynamics}

Ramsey dynamics. We analyze the model dynamics, in the case of Ramsey optimum through impulse response functions (IRFs henceforth). We look at the optimal dynamics in response to a positive technology and to a negative markup shock.

- Figures 3 and 4 about here -

Figure 3 shows the impulse response functions (IRFs) of the main macroeconomic variables to a $1 \%$ increase in technology. We consider the fully Ricardian case $(\lambda=0$, dotted lines) and the case in which the fraction of liquidity constrained consumers is $\lambda=0.3$ (dashed lines) and $\lambda=0.5$ (solid lines). ${ }^{15}$ As expected, in all cases policy makers accommodate the shock to boost the economy by reducing nominal interest rates and raising public expenditure. The authorities commit, this is why the resulting optimal dynamics feature price stability and a persistent increase of aggregate output, no matter the value of $\lambda$.

In response to a negative price markup shock we get different results. Figure 4 shows the IRFs of the same macroeconomic variables to a $1 \%$ increase in the elasticity of substitution among intermediate goods (which implies a reduction in firms markup). The optimal IRFs to a markup shock imply deviation from price stability, a positive public

\footnotetext{
${ }^{14}$ Finally we also find that both the FL and the ML game under a fully conservative monetary policy, that is with $\alpha=1$, imply price stability as in Ramsey. As a consequence, also the optimal steady state nominal interest rate necessary to obtain price stability is the same as in Ramsey under the two games. The optimal Government spending is instead slightly higher under the ML game than under the the FL game and it does not coincide with that of the Ramsey planner. Indeed, in the ML game, the fiscal authority moves second and thus it cannot internalize the behavior of the ML, leading to an excessive spending with respect to Ramsey and to the FL game. For space constraint we do not report the results of the ML and the FL game with $\alpha=1$. Results are however available under request.

${ }^{15}$ The choice is justified since the literature reports estimated values of $\lambda$ in between 0.3 and 0.5. Note also that for inflation and the interest rate we plot annualized variations in percentage points.
} 
spending and an increase in output. Deviation from price stability seems moderately affected by LAMP. However, for high enough values of $\lambda$ this is achieved through a small reduction of the nominal interest rate, which leaves the real rate almost unchanged. ${ }^{16}$ Interestingly, public spending instead increases as the fraction of liquidity constrained agents gets higher. Furthermore, the response on impact of public spending is significantly higher (in absolute value) and the effect of the shock is reabsorbed after more periods than in the benchmark model. Summing up, an increasing boost to public expenditure and a greater reduction in interest rates are needed to sustain welfare as $\lambda$ increases.

Nash dynamics. Under Nash some differences emerge with respect to Ramsey dynamics. Figures 5 and 6 depict the optimal IRFs of the main macroeconomic variables to a persistent technology shock and markup shock, for the same values of $\lambda$.

- Figures 5 and 6 about here -

In response to a technology shock, the lack of commitment produces a rise in inflation and an increase in output. The response of inflation increases as $\lambda$ increases. This happens because the monetary authority is aimed at reducing the higher distortion coming from the increase of per capita profits, which otherwise would lower aggregate output. Remarkably, hours worked fall. The contraction in hours following a positive productivity shock is in line with recent US evidence (see, for example, Galí and Rabanal, (2004)). The reduction of labor hours increases with $\lambda$. The intuition for these results is the following. The monetary policy is not forward looking, it decides period by period and thus generates higher inflation by lowering interest rates. This stimulates aggregate demand and increases Ricardian consumption. The aggregate demand is also stimulated by an increase in public spending, which, together with the accommodative monetary policy, contributes to push output and inflation up. At the same time, as $\lambda$ increases, per capita profits increase giving an additional boost to Ricardian consumption. This in turn reduces their labor supply due to the wealth effect between consumption and leisure. On the contrary, public spending is not affected by $\lambda$.

\footnotetext{
${ }^{16}$ Precisely, starting from $\lambda=0.42$ the optimal response of the interest rate turns negative.
} 
The IRFs relative to the markup shock are represented in Figure 6. The fiscal policy responds by reducing $G_{t}$ on impact.

Since firms' markup reduces, firms supply more output and, ceteris paribus, increase their labor demand, so that real wages increase. ${ }^{17}$ Liquidity constrained consumption rises due to the higher real wage and to the huge reduction of public spending and thus of taxes. At the same time, as in standard RBC models, Ricardians' consumption $C_{t}^{o}$ goes up as public spending decreases, due to the positive wealth effect. The response of public spending is stronger as $\lambda$ increases, while for the real wage the opposite holds. Aggregate output increases less than in the RAE economy for $\lambda=0.3$, while decreases on impact for $\lambda=0.5$. The negative response of output is mainly due to the negative response of aggregate hours. Indeed, as $\lambda$ passes from 0.3 to 0.5 , LC consumption increases less, due to the lower rise of real wages, thus generating a slightly lower decrease in their labor supply. At the same time, the lower interest rate, together with the increase in per capita profits, make Ricardians' consumption go up more, so that their labor supply switches from positive to negative, thus generating the negative response of aggregate hours. Differently, for $\lambda=0$ and $\lambda=0.3$ the impact effect on hours and thus output is positive: the greater increase of real wages and the lower rise of consumption cause labor supply to augment and so does output.

Fiscal Leader dynamics. With $\alpha=0.5$, i.e. with a partially conservative monetary policy, the optimal dynamics under the Fiscal leadership change only marginally with respect to the Nash case. For this reason we do not show the figure relative to this particular game. $^{18}$

Monetary Leader dynamics. With a partially conservative monetary policy, the optimal dynamics under the Monetary leadership change only marginally with respect to Nash and the FL game with $\alpha=0.5{ }^{19}$

\footnotetext{
${ }^{17}$ Remember that, when productivity is constant, real wages coincide with firms' real marginal costs which, in turn, are the inverse of firms' markup.

${ }^{18}$ Results are available upon request.

${ }^{19}$ For this reason we do not show the figure relative to this particular game, results are however available upon request. Further, notice that with $\alpha=1$ the same considerations found for the steady state analysis hold.
} 
Overall, we find that the results are mainly driven by the dicretionary behavior of the policy authorities, while they are not particularly affected by the type of the dicretionary game considered.

\subsection{The optimal inflation volatility}

We now focus on the implied optimal inflation volatility under the different policy regimes - Figure 7 shows the optimal inflation volatility for $\lambda \in(0,0.6)$ when the economy is hit by technology and markup shocks simultaneously. First of all notice that, as expected, the optimal inflation volatility is always greater under Nash than under Ramsey. Second, both under Ramsey and the Nash game the volatility of inflation increases with $\lambda$, even though under Nash the pace of inflation volatility is significantly higher than under Ramsey. This occurs because the increase in the volatility of inflation in only due to the markup shocks under Ramsey. Indeed in this case, the volatility of inflation is always zero in response to a technology shock, no matter the value of $\lambda .^{20}$

- Figure 7 about here -

The presence of a positive inflation volatility which increases with $\lambda$ is motivated by the optimal behavior of the Central Bank which makes use of the inflation rate as a tax on profits. As stated before, since per capita profits increases as the fraction of liquidity constrained consumers increases, the larger $\lambda$ the higher will be the volatility of inflation.

The results under FL and ML are only marginally different with respect to Nash. Thus, confirming that is the discretionary behaviour of the authorities that mainly drives the results.

\section{$5 \quad$ Welfare analysis}

In this section we show a measure for the utility losses associated to a particular game structure. We calculate the percent loss of each game structure with respect to the Ramsey

\footnotetext{
${ }^{20}$ Results are available upon request.
} 
deterministic steady state. Denote $V^{R}=\left[\lambda u\left(C^{r}, N^{r}, G\right)+(1-\lambda) u\left(C^{o}, N^{o}, G\right)\right] /(1-$ $\beta$ ) the utility for the Ramsey deterministic steady state and $V^{A}$ the stochastic steady state of the value function of an alternative policy regime. The permanent reduction in private consumption, $\mu^{A} \leq 0$ (supposing to withdraw the same amount from each type of consumer), that would imply the Ramsey deterministic steady state to be welfare equivalent to the alternative policy regime can be found solving for $\mu^{A}$ the following expression:

$$
V^{A}=\frac{1}{1-\beta}\left[\lambda u\left(C^{r}\left(1+\mu^{A}\right), N^{r}, G\right)+(1-\lambda) u\left(C^{o}\left(1+\mu^{A}\right), N^{o}, G\right)\right] .
$$

We use the same formulas to evaluate welfare for each type of consumer, i.e., $V_{h}^{R}=$ $u\left(C^{h}, N^{h}, G\right) /(1-\beta)$, and

$$
V_{h}^{A}=\frac{1}{1-\beta}\left[u\left(C^{h}\left(1+\mu_{h}^{A}\right), N^{h}, G\right)\right]
$$

where $h \in(r, o)$ identifies the two types of consumers.

Table 3 shows the welfare losses in percentage terms resulting from the RAE model and the model with liquidity constrained consumers for each policy regime and distinguishing between total, Ricardian and liquidity constrained welfare. ${ }^{21}$ What we note is that the Nash equilibrium leads to a total welfare loss which is bigger than the Fiscal Leadership and Monetary Leadership cases where the monetary policy is partially conservative about inflation.

Notably, Table 3 shows that the Nash game, the FL and the ML with partially conservative monetary policy involve a loss of welfare for Ricardians while liquidity constrained consumers experience a gain. This is due to the fact that under these types of policy regimes the equilibrium implies an inflation bias which makes per capita profits lower. On the contrary, the higher production with respect to the Ramsey allocation implies a higher real wage which has a direct positive effect on liquidity constrained agents consumption, thus raising their welfare.

\footnotetext{
${ }^{21}$ Note that we cannot compare total welfare losses for different values of $\lambda$, but only for different types of policy regimes. Also, note that individual welfare losses/gains do not depend directly on $\lambda$.
} 
When monetary policy is partially conservative, this result still holds, even if the loss in terms of welfare of Ricardians is slightly lower, due to the fact that the inflation bias is marginally dampened by conservatism of monetary policy.

Summing up, we can state that under the Nash game, the Fiscal Leadership and the Monetary Leadership game with partially conservative Central Bank, liquidity constrained consumers experience a welfare gain with respect to Ramsey, while Ricardians a welfare loss. This result suggests that when the monetary authority and the fiscal authority play strategically, a sort of implicit redistribution characterizes the economy, since agents with lower income, i.e. LAMP consumers, experience a welfare gain, while Ricardian get a loss of welfare.

\begin{tabular}{r|c|ccc|ccc}
\hline \hline & RAE & \multicolumn{3}{|c|}{$\lambda=0.3$} & \multicolumn{3}{c}{$\lambda=0.5$} \\
\hline \hline & total & total & Ricardians & LC & total & Ricardians & LC \\
\hline Nash & -1.03 & -2.30 & -3.42 & 0.38 & -5.18 & -10.60 & 0.57 \\
Fiscal Leader with $\alpha=0.5$ & -1.01 & -2.26 & -3.36 & 0.38 & -5.10 & -10.44 & 0.56 \\
Monetary Leader with $\alpha=0.5$ & -1.02 & -2.27 & -3.38 & 0.37 & -5.02 & -10.33 & 0.60 \\
\hline \hline
\end{tabular}

Table 3: Welfare losses from Ramsey allocations in consumption equivalents (percentages)

Figures 8, 9 and 10 show the optimal responses of welfare under the three different policy regimes considered and under Ramsey. In order to make the dynamics of the different games comparable, for each game we compute the log-deviations with respect to the Ramsey steady state. Thus, an IRF lower (higher) than the corresponding one under Ramsey, simply implies that for the policy considered welfare is lower (higher) than Ramsey in the short run. We first compare the responses of the different regimes under RAE and then we show the same responses under the LAMP economy.

Notice that under RAE in response to a technology shock welfare responses are positive under all the policy regimes, since a positive technology shock implies a welfare improvement. However, the implied welfare is always lower than Ramsey's no matter the policy game considered (see figure 8). Further, the three policy regime show very similar welfare dynamics. In response to a markup shock the responses of welfare are still positive under Ramsey (even if close to zero), while they become negative under the other three games considered. As before, the three policy games do not differ substantially in terms 
of welfare dynamics.

Figures 9 and 10 show welfare IRFs of the two agents (Ricardian versus LAMP) in the LAMP economy. Also in this case we compare the implied IRFs with that of the Ramsey planner. We set the share of LAMP consumers $\lambda=0.3$ (See Figure 9) and $\lambda=0.5$ (see Figure 10). Notice that, for all the games considered, the welfare response of Ricardians' is qualitatively similar to the one implied by the RAE economy and always below the aggregate welfare IRFs implied by the Ramsey regime in the LAMP economy. On the contrary, for each policy regimes considered the welfare response of LAMP consumers is close to the Ramsey one. This implies that LAMP are always better off than Ricardians, no matter the value of $\lambda$ and the shock considered. Finally, the results are not sensible to the game considered.

\section{Conclusions}

In this paper we investigate the effects of the presence of a fraction of consumers who cannot smooth consumption and have no access to state-contingent markets nor receive dividends, on optimal policy responses both in the long-run and in the short run. We compare our results to the fully Ricardian model. Concerning the long-run equilibrium, we find that under the Nash game and the Fiscal Leadership game with partially conservative Central Bank, the optimal monetary policy implies an inflation bias which strongly increases as the fraction of liquidity constrained consumers increases. This happens because the monetary policy aims at reducing the monopolistic distortion, which increases as LAMP gets higher.

Analyzing the optimal responses in face of positive technology and negative price markup shocks, we find that LAMP plays an important role also under Ramsey. In this case, in fact, the optimal responses to a negative markup shock imply deviation from price stability and positive public spending. Moreover, as the fraction of liquidity constrained agents gets higher public spending increases more and more. The presence of liquidity constrained consumers alters quantitatively also the reaction of discretionary policies. In this case, in response to both shocks optimal inflation volatility gets higher as the fraction 
of LC consumers increases.

Finally, we find that contrary to what happens to Ricardian consumers, under discretionary policy regimes liquidity constrained agents get a welfare gain, thus implying a sort of implicit redistribution from Ricardians to LC consumers.

Further developments of this study include the possibility of considering different fiscal structures, given that the balanced budget requirement is a very simplifying assumption and it is not always such a proper description of a country's fiscal structure. It would also be interesting to have a game structure where there are several fiscal authorities playing with a unique monetary authority, which is a case very close to the EU context.

\section{Acknowledgements}

We thank Guido Ascari for helpful comments. We also thank Evi Pappa and Stefano Gnocchi together with the seminar participants at Universitat Autonoma de Barcelona and University of Pavia. The authors thank the Foundation Alma Mater Ticinensis for financial support through the research grant "Promuovere la ricerca d'eccellenza".

\section{References}

Adam, K. and R. M. Billi (2008). Monetary conservatism and fiscal policy. Journal of Monetary Economics 55, 1376-1388.

Albonico A., A. Paccagnini and P. Tirelli (2014). Estimating a DSGE model with Limited Asset Market Participation for the Euro Area, Working Papers 286, University of Milano-Bicocca, Department of Economics.

Albonico, A., A. Paccagnini and P. Tirelli (2016a). In search of the Euro Area Fiscal Stance, forthcoming on the Journal of Empirical Finance.

Albonico, A., A. Paccagnini and P. Tirelli (2016b). Great Recession, Slow Recovery and Muted Fiscal Policies in the US, forthcoming on the Journal of Economic Dynamics and Control.

Albonico A. and L. Rossi (2015). Policy Games, Distributional Conflicts, And The 
Optimal Inflation, Macroeconomic Dynamics, Cambridge University Press, vol. 19(06), pages 1261-1293.

Ascari, G., A. Colciago and L. Rossi (2011). Limited asset market participation: does it really matter for monetary policy?, Research Discussion Papers 15/2011, Bank of Finland.

Beetsma, R. and H. Jensen (2005). Monetary and fiscal policy interactions in a microfounded model of a monetary union. Journal of International Economics 67(2), 320-352.

Bilbiie, F. O. (2008). Limited asset market participation, monetary policy and (inverted) aggregate demand logic. Journal of Economic Theory 140, 162-196.

Campbell, J.Y. and N. Gregory Mankiw (1989). Consumption, income and interest rates: Reinterpreting the time series evidence. NBER Chapters, in: NBER Macroeconomics Annual 4, 185-246.

Colciago A. (2011). Rule-of-thumb consumers meet sticky wages. Journal of Money, Credit and Banking 43, 325-353.

Di Bartolomeo, G. and L. Rossi (2007). Effectiveness of monetary policy and limited asset market participation: Neoclassical versus Keynesian effects. International Journal of Economic Theory 3, 213-218.

Forni, L., L. Monteforte and L. Sessa (2009). The general equilibrium effects of fiscal policy: Estimates for the Euro area. Journal of Public Economics 93(3-4), 559-585.

Furlanetto Francesco (2011). Fiscal stimulus and the role of wage rigidity. Journal of Economic Dynamics and Control 35(4), 512-527.

Galí, J., D. López-Salido, and J. Vallés (2004). Rule-of-thumb consumers and the design of interest rate rules. Journal of Money, Credit and Banking 36, 739-764.

Galí, J., D. López-Salido, and J. Vallés (2007). Understanding the effects of government spending on consumption. Journal of the European Economic Association 5 (1), $227-270$.

Galí, J. and P. Rabanal (2004). Technology shocks and aggregate fluctuations: How well does the RBC model fit postwar U.S. data? In M. Gertler and K. Rogoff (Eds.), NBER Macroeconomics Annual, 225-288. Cambridge, MA: The MIT Press. 
Gnocchi, S. (2008). Discretionary fiscal policy and optimal monetary policy in a currency area. Working Paper No. 602, Economics Department of Bologna University.

Kaplan G., G. Violante and J. Weidner (2014), The Wealthy Hand-to-Mouth, Brookings Papers on Economic Activity, pages 77-123.

Mankiw, N.G. (2000).

Motta G. and P. Tirelli (2012). Optimal Simple Monetary and Fiscal Rules under Limited Asset Market Participation, Journal of Money, Credit and Banking, 44(7), 13511374.

Muscatelli, V. A., P. Tirelli and C. Trecroci (2004). Fiscal and monetary policy interactions: Empirical evidence and optimal policy using a structural New-Keynesian model. Journal of Macroeconomics 26(2), 257-280.

Rabanal, P. and J.F. Rubio-Ramirez (2005). Comparing New Keynesian models of the business cycle: A Bayesian approach, Journal of Monetary Economics, Elsevier, vol. $52(6), 1151-1166$.

Rogoff, K. (1985). The optimal degree of commitment to a monetary target. Quarterly Journal of Economics 100(4), 1169-1190.

Rotemberg, J.J. (1982). Sticky prices in the united states. Journal of Political Economy $90,1187-1211$.

Schmitt-Grohé S. and Uribe M (2004a). Optimal fiscal and monetary policy under imperfect competition. Journal of Macroeconomics 26, 183-209.

Schmitt-Grohé, S. and Uribe M. (2004b). Optimal fiscal and monetary policy under sticky prices. Journal of Economic Theory 114, 198-230.

Schmitt-Grohé, S. and M. Uribe (2007). Optimal simple and implementable monetary and fiscal rules. Journal of Monetary Economics 54 (6), 1702-1725.

Smets F. and R. Wouters (2003). An Estimated Dynamic Stochastic General Equilibrium Model of the Euro Area, Journal of the European Economic Association, MIT Press, vol. 1(5), pp. 1123-1175.

Smets F. and R. Wouters (2007). Shocks and Frictions in US Business Cycles: A Bayesian DSGE Approach, American Economic Review, American Economic Association, 
vol. 97(3), pp. 586-606.

\section{Figures}

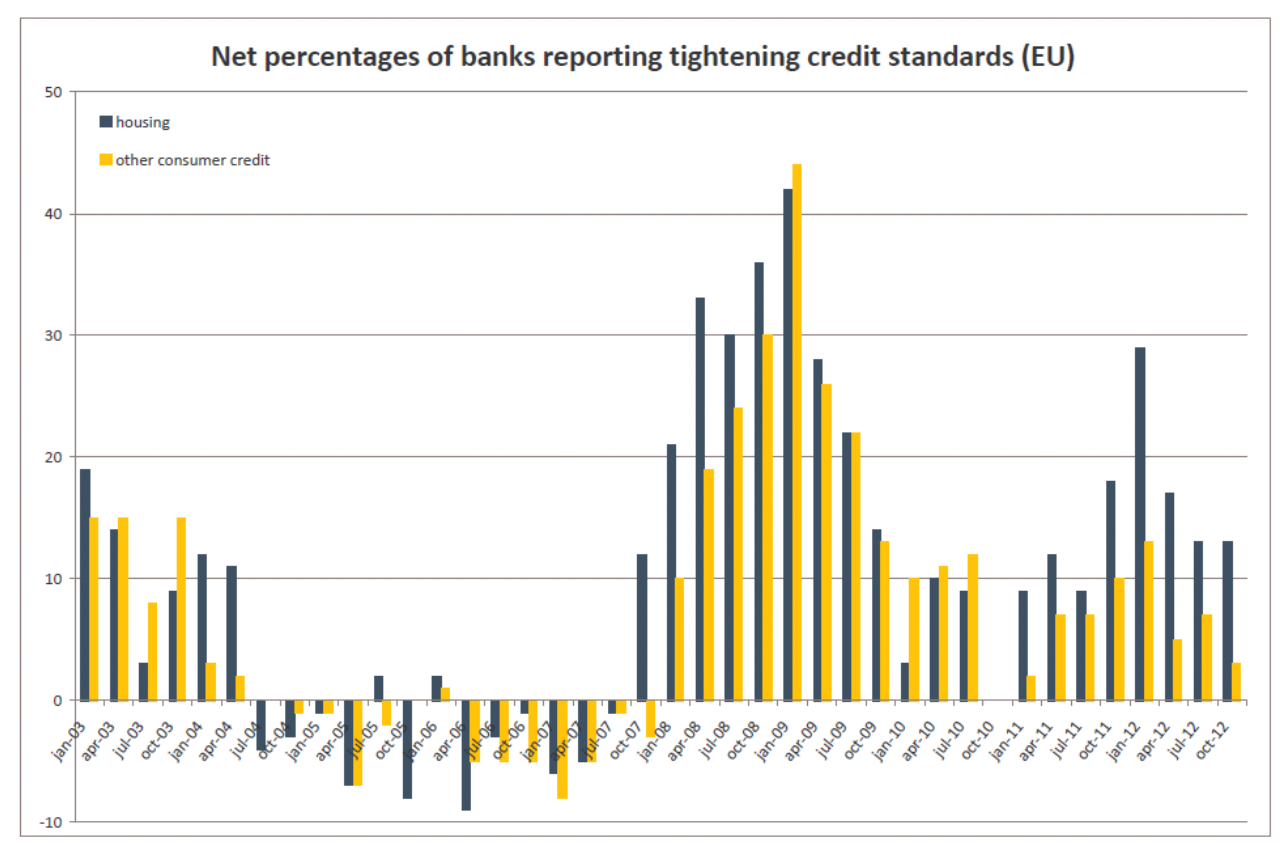

Fig. 1. Credit standards in the EU economy.

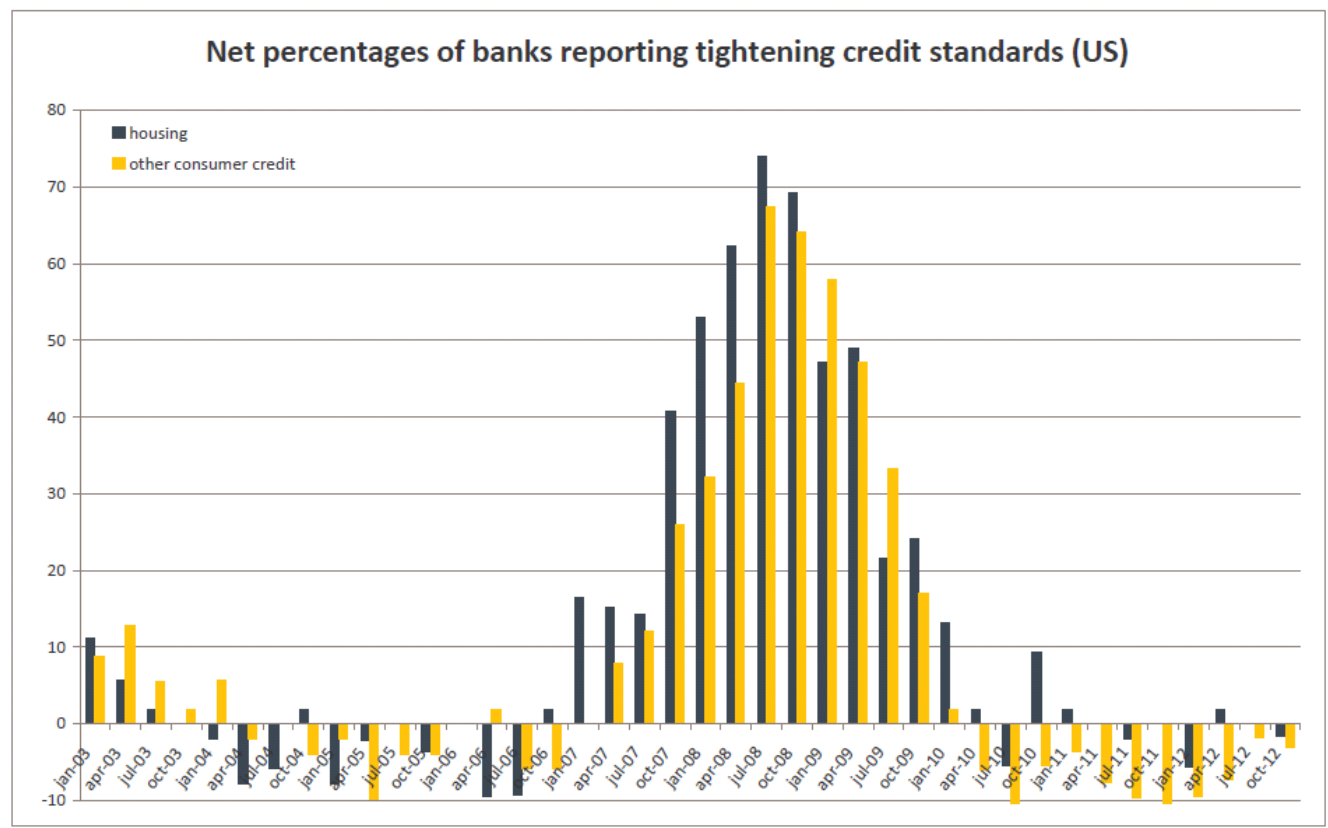

Fig. 2. Credit standards in the US economy. 

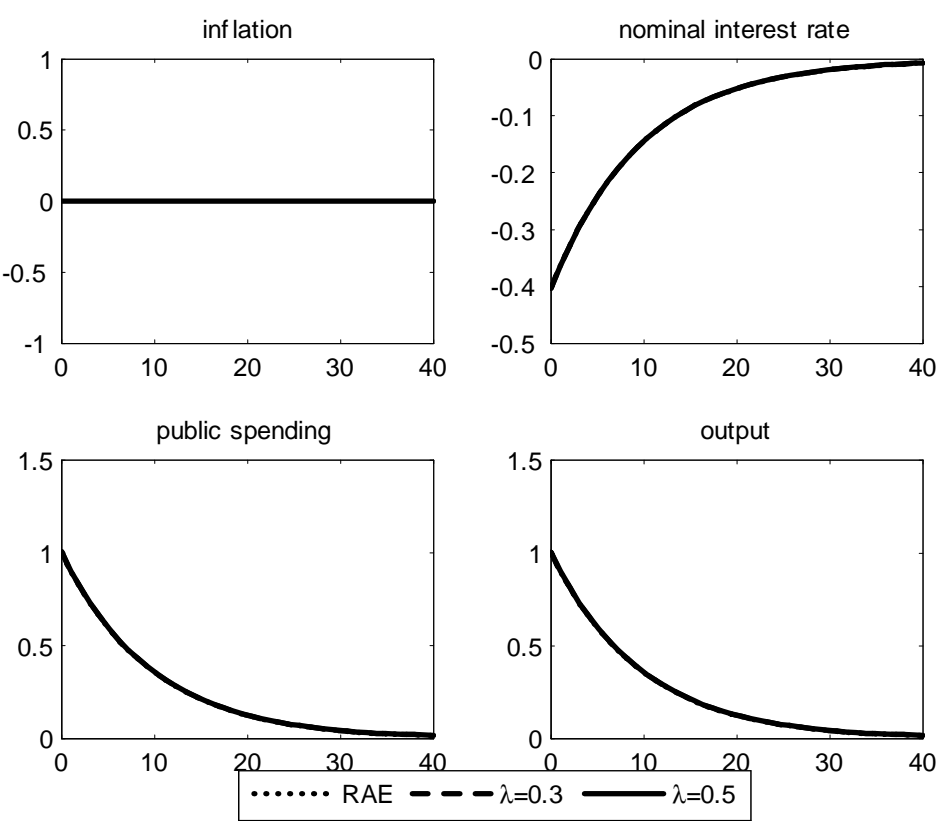

Fig. 3. Ramsey IRFs to a $1 \%$ positive technology shock under the baseline model with $\lambda=0.3$ (dashed lines) and $\lambda=0.5$ (solid lines) and the RAE model (dotted lines).
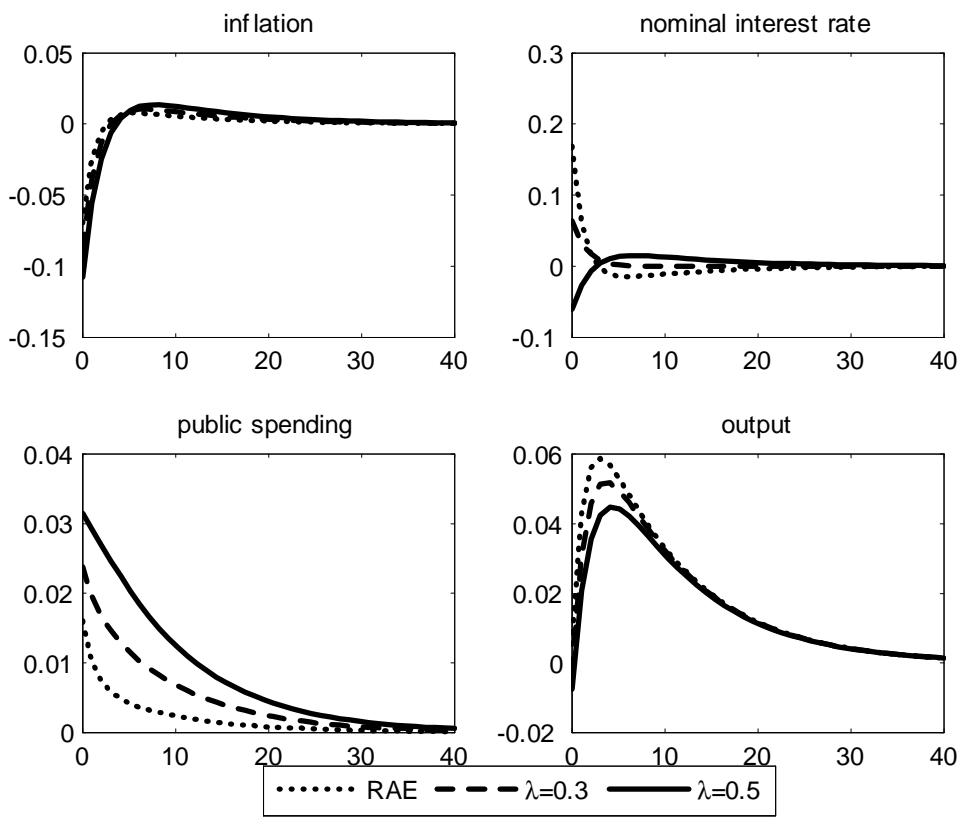

Fig. 4. Ramsey IRFs to a $1 \%$ negative markup shock under the baseline model with $\lambda=0.3$ (dashed lines) and $\lambda=0.5$ (solid lines) and the RAE model (dotted lines). 

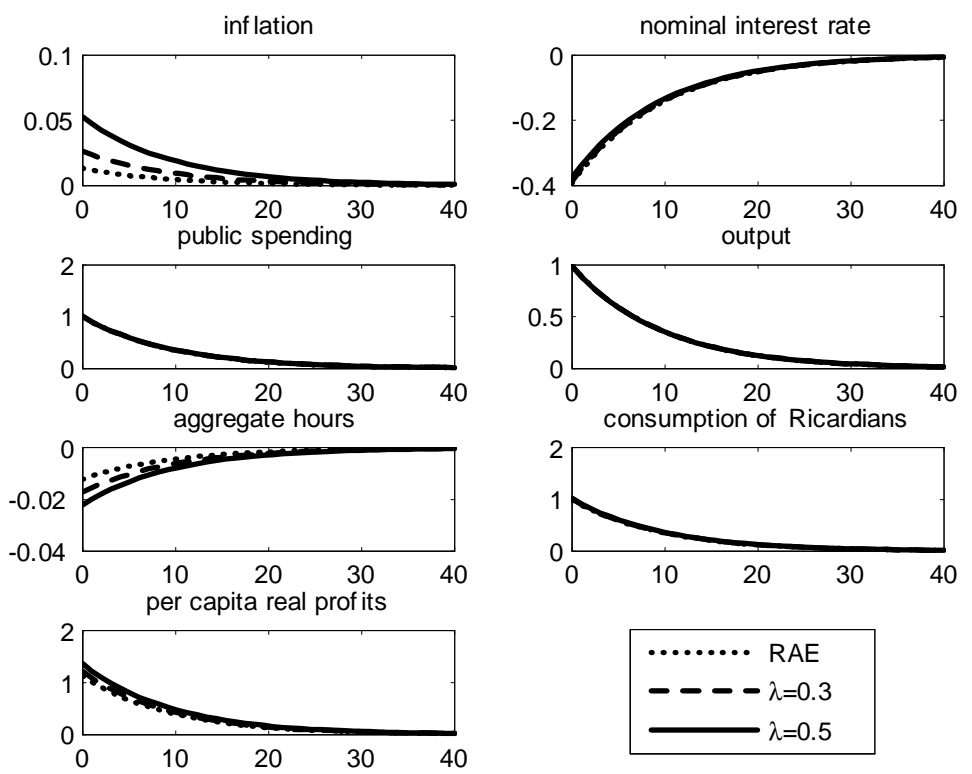

Fig. 5. Nash IRFs in response to a $1 \%$ positive technology shock under the baseline model with $\lambda=0.3$ (dashed lines) and $\lambda=0.5$ (solid lines) and the RAE model (dotted lines).
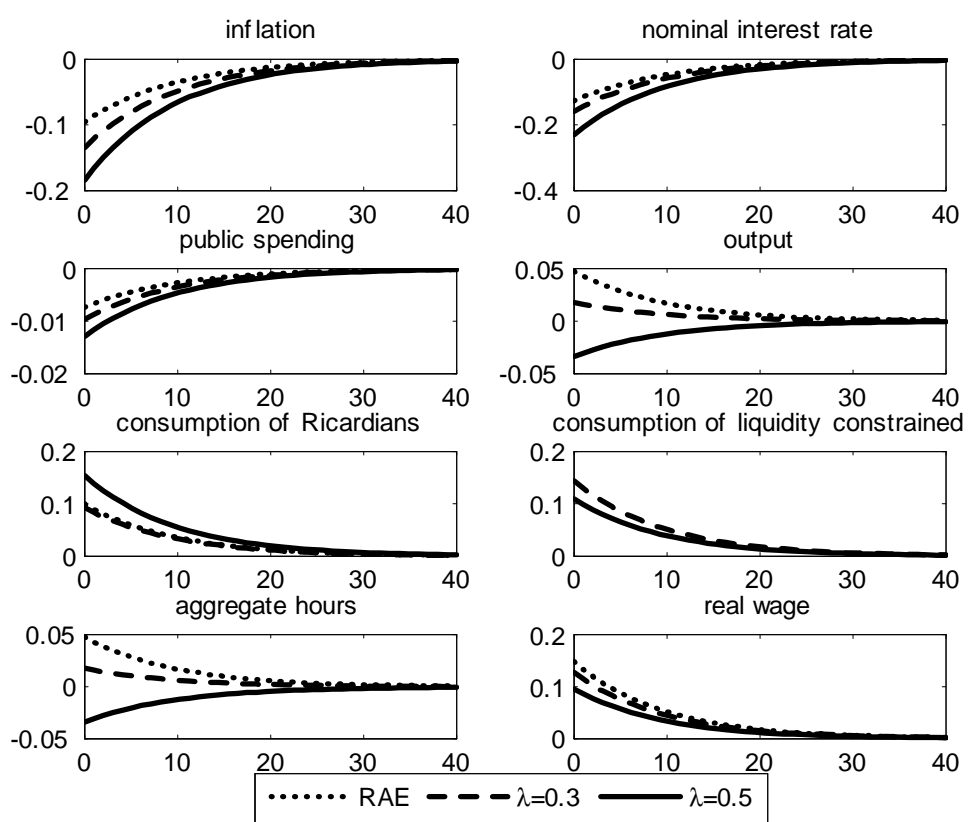

Fig. 6. Nash IRFs to a $1 \%$ negative markup shock under the baseline model with $\lambda=0.3$ (dashed lines) and $\lambda=0.5$ (solid lines) and the RAE model (dotted lines). 


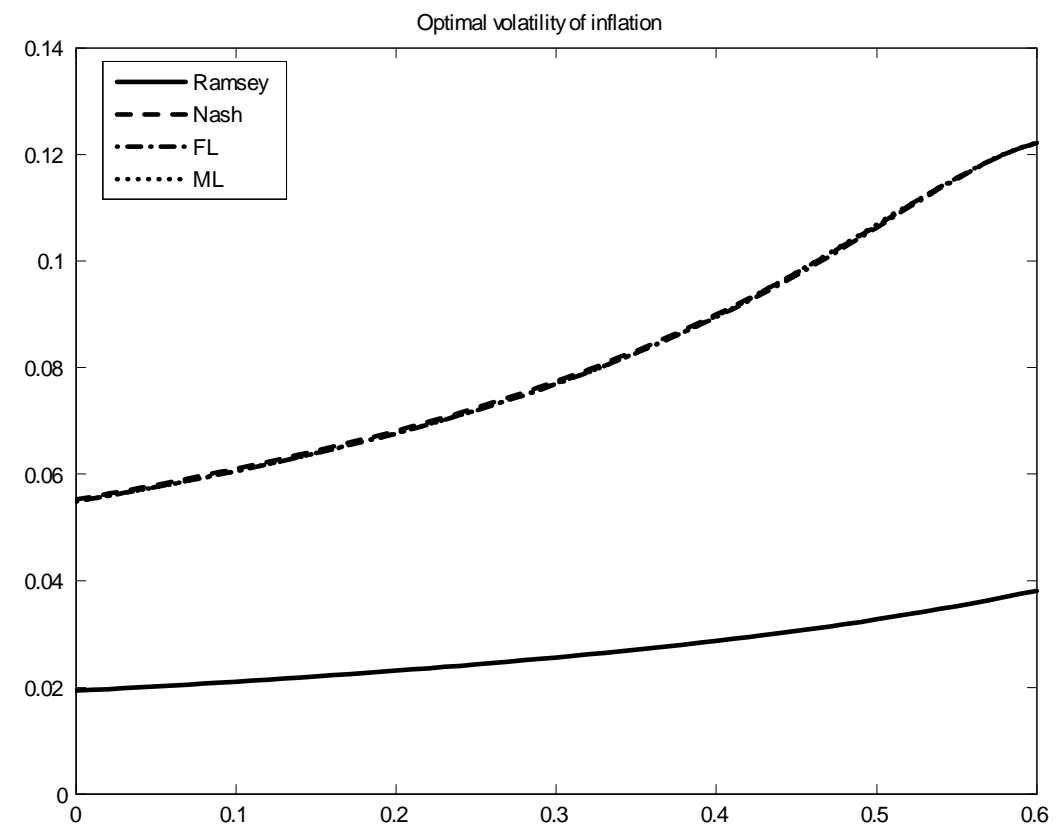

Fig. 7. LAMP and Optimal inflation volatility.
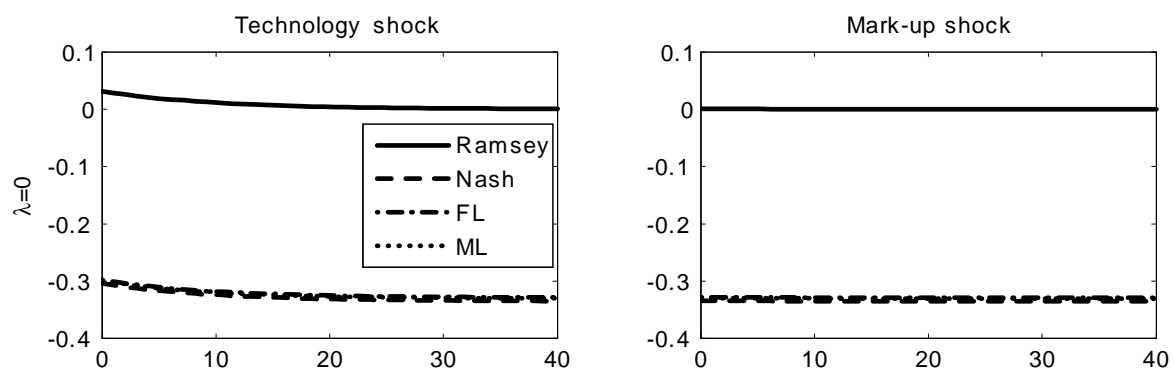

Fig. 8. Welfare IRFs under RAE.
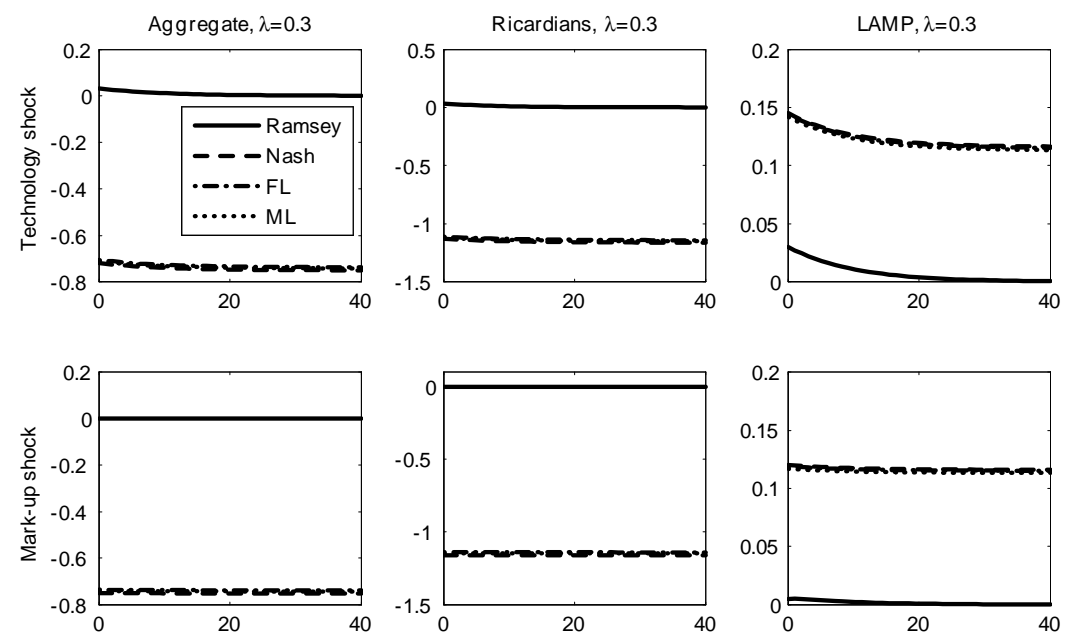

Fig. 9 .Welfare IRFs with $\lambda=0.3$. 

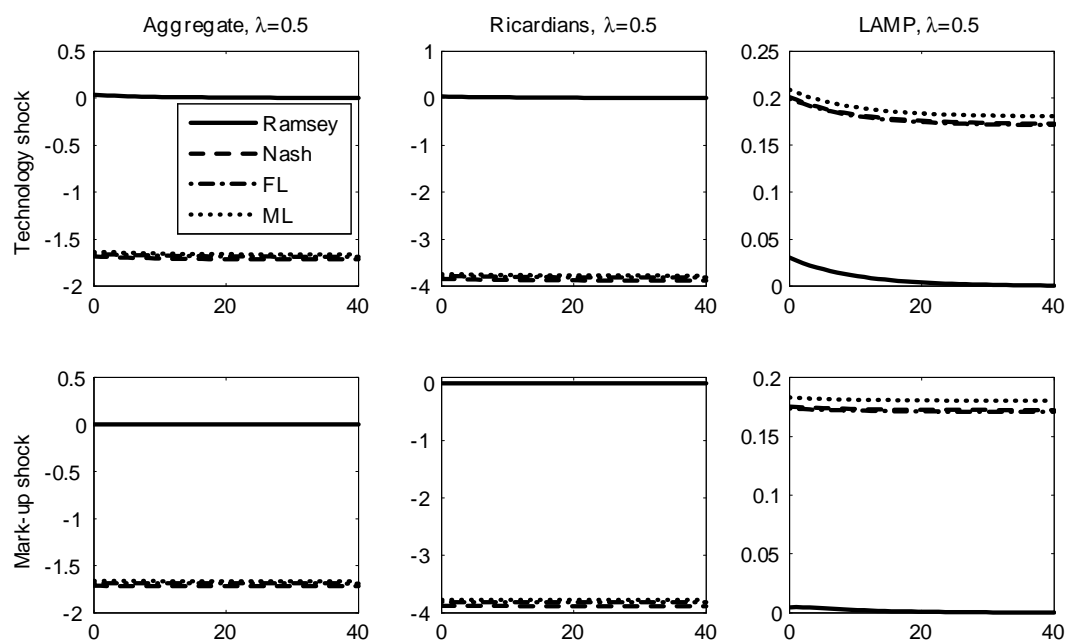

Fig. 10. Welfare IRFs with $\lambda=0.5$. 